CIUDAD Y TERRITORIO

ESTUDIOS TERRITORIALES

ISSN(P): 1133-4762; ISSN(E): 2659-3254

Vol. LII, № 203, primavera 2020

Págs. $13-32$

https://doi.org/10.37230/CyTET.2020.203.02

CC BY-NC 4.0

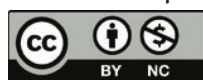

\title{
Ciudades sostenibles y género: el compromiso de las redes de mujeres para la Nueva Agenda Urbana
}

Teresa BoccIA

Profesora LUPT, Universidad Federico II de Nápoles, miembro de AGGI, Grupo Asesor de Género de ONU-Habitat, Presidenta del Grupo de Mujeres de la Asamblea General de Socios de ONU-Habitat

RESUMEN: La Nueva Agenda Urbana (NAU), aprobada en la Conferencia Hábitat III de las Naciones Unidas sobre la Vivienda y el Desarrollo Urbano Sostenible ofrece una magnífica oportunidad para abordar las desigualdades de género en las áreas urbanas, con una nueva visión de las ciudades del futuro como motor para el desarrollo económico, la prosperidad, la igualdad de oportunidades, la inclusion social y la justicia de género. Las redes de mujeres, que han sido agentes eficaces en la redacción de todas las agendas internacionales de desarrollo sostenible, han acompañado, también, con una gran movilización todo el largo y complejo camino de construcción de la Nueva Agenda Urbana, que es resultado de un extenso proceso de consultas y participación de tres años. El trabajo conjunto de académicas y mujeres de base en diferentes organizaciones, jugó un papel muy importante para introducir la perspectiva de género en la NAU y continúa con tenacidad en todo el proceso de implementación, para que las palabras se conviertan de manera concreta en políticas estructurales para el cambio y la igualdad.

PALABRAS CLAVE: Ciudades sostenibles. Género. Nueva Agenda Urbana. Redes de mujeres. Participación.

\section{Sustainable cities and gender: the commitment of women's networks to the New Urban Agenda}

ABSTRACT: The New Urban Agenda (NAU), approved at the United Nations Habitat III Conference on Housing and Sustainable Urban Development offers a magnificent opportunity to address gender inequalities in urban areas, with a new vision of the cities in the future as engines for economic development, prosperity, equal opportunities, social inclusion and gender justice. Women's networks, which have been effective agents in the drafting of all international sustainable development agendas, have also accompanied, with great mobilization, the entire long and complex way of building the New Urban Agenda, which is the

Recibido: 10129/.2019; Revisado: 11.12.2019

Correo electrónico: boccia@unina.it 
result of an extensive three-year consultation and participation process. The joint work of academics and women in different organizations, played a very important role in introducing the gender perspective in the New Urban Agenda and continues with tenacity throughout the implementation process, so that words can turn specifically into structural policies for change and equality.

\section{KEYWORDS: Sustainable cities. Gender. New Urban Agenda. Women's networks. Participation.}

\section{Contexto y marco teórico}

- I proceso de urbanización en el mundo no se puede parar: el siglo XXI es un siglo de crecimiento demográfico y también un siglo urbano ${ }^{1}$. Es un desafío sin precedentes en la historia de la humanidad: en 40 años, cuatro de cada cinco personas vivirán en la ciudad. Europa se ha convertido en uno de los continentes más urbanizados del planeta, con una expansión incontrolada que consume suelo incluso sin crecimiento de población ${ }^{2}$.

Estamos consumiendo la tierra y provocando cambios irreversibles, modificando los ecosistemas y consumiendo los recursos del mundo con una nueva economía global que se materializa en nuevas formas espaciales: megalópolis de esclavitud y metrópolis capitalistas, hiperconectadas externamente a redes financieras y productivas globales, desconectadas de una gran parte de las poblaciones locales, que se vuelven socialmente disruptivas debido a su precariedad.

La financiarización exagerada de la economía conduce a una distribución creciente y desequilibrada de la riqueza. Entonces, por un lado, hay migraciones salvajes, alimentadas también por el aumento de las guerras y los conflictos, con un alto costo de vidas humanas, y por el otro, el nacimiento de barrios marginales, barrios informales, suburbios y pobreza concentrada a límites de la supervivencia. La crisis económica, y el desarrollo mismo de innovaciones tecnológicas vinculadas a

\footnotetext{
${ }^{1}$ La población mundial continúa creciendo: estábamos alrededor de 2 mil millones en 1927 y 6 mil millones a fines del siglo XX ahora somos alrededor de 7,7 mil millones. Las proyecciones a 30 años muestran que en 2050 alcanzaremos 9.700 millones y todos los indicadores sugieren que a fines de siglo, en 2100 , seremos 11.000 millones de personas. La concentración de crecimiento será en los países más pobres, más de la mitad hasta 2050 en África, con un número de jóvenes que representan aproximadamente el $42 \%$ de la población. El $90 \%$ de los jóvenes del mundo viven en África, Asia y América Latina, donde se concentran la pobreza, ladesigualdad, el hambre y la malnutrición, la falta de los sistemas educativos y de salud, mientras que en las otras regiones hay un envejecimiento significativo, comenzando con Europa, donde se piensa que el 34\% de la población tendrá más de 60 años para 2050. Véase a respecto UN DESA: World Population Prospects 2019, Highlights.

2 La mitad de la humanidad, 3500 millones de personas, vive hoy en día en las ciudades y se prevé que esta cifra
}

las TIC, están aumentando las contradicciones y las brechas entre países, territorios y personas, y transformando el modelo social de las economías avanzadas.

En estos complejos cambios urbanos, las ciudades están llenas de barreras creadas por la modernidad líquida3: fragmentación y segregación espacial y social, con muchos barrios reducidos a "vida desnuda", sin agua potable, saneamiento, electricidad, transporte, servicios básicos y espacios comunes. En estos lugares sin historia y sin memorias ${ }^{4}$, donde el futuro es un horizonte cansado de expectativas que nunca tienen respuestas, se multiplican los espacios habitados por personas sin hogar $^{5}$, casi una ciudad en la ciudad, y con una larga lista de los invisibles -también en Europa- donde a los inmigrantes y a los desempleados, se unen las personas mayores que viven solas, trabajadores ocasionales, padres y madres separadas.

Muchas ciudades en el mundo están cercadas, fragmentadas, privatizadas y muchas de estas áreas de exclusión social corren el riesgo de convertirse en áreas de conflicto espacial y social entre las clases más débiles, las personas empobrecidas y migrantes sin colocación. Por otra parte, estos lugares de grandes desigualdades sociales, económicas y culturales están siempre marcados por una falta del ejercicio de la ciudadanía.

En el contexto de estas desigualdades, las mujeres son, con gran diferencia, quienes sufren más, son pobres entre los pobres, e, históricamente, tienen

aumentará a 5000 millones para el año 2030. El 95\% de la expansión de los terrenos urbanos en las próximas décadas tendrá lugar en el mundo en desarrollo.

${ }^{3}$ Bauman, Zygmunt: Liquid Modernity, Cambridge: Polity Press. 2000.

${ }^{4}$ Como señaló Hannah ARENDT, la memoria permite mantener un vínculo entre los tiempos del pasado y los tiempos del futuro que son percibidos por el sujeto y le dan sustancia al presente, mientras que lo que es olvidado o eliminado nos permite percibir la brecha entre el pasado y nuestro presente. ARENDT H, Quaderno I, 4 , julio 1950.

5 Según las estimaciones de la ONU, más de 100 millones de personas en el mundo no tienen acceso a ningún tipo de vivienda. Los Objetivos de Desarrollo Sostenible (ODS) incluyen en su meta 11.1 "asegurar el acceso de todas las personas a viviendas y servicios básicos adecuados, seguros y asequibles para el año 2030". 
más invisibilidad. ${ }^{6}$ Es cierto que la feminización de la pobreza es muy alta en las zonas urbanas. Esto es especialmente en los hogares encabezados por mujeres, migrantes, refugiadas, que viven y/o vienen a la ciudad para buscar mejores oportunidades de vida y que no tienen más remedio que instalarse en los suburbios, barrios marginales, contaminados y sin derechos. No solo sin derechos económicos sino también sin educación, salud, transporte asequible y seguridad.

Muchas mujeres no trabajan, muchas están empleadas en trabajos informales, mal pagados o en trabajos precarios y en puestos vulnerables e, incluso entre quienes trabajan, son pocas en los puestos más altos y a menudo reciben un salario diferente por el mismo trabajo. ${ }^{7}$ Son datos relevantes y el lema "que nadie se quede atrás"8 adoptado por la Agenda 2030 y la Nueva Agenda Urbana, tiene sentido solo si se considera como prioridad la igualdad de género sustancial como elemento estructural para el cambio, porque no se refiere a un grupo, sino a la mitad de la población en el mundo.

La investigación de la planificación urbana se ha ocupado durante mucho tiempo de las relaciones de clase y de los conflictos en las ciudades, pero, así como las teorías económicas y los análisis políticos han favorecido las actividades productivas, dejando las reproductivas a la sombra, poco se ha interesado de las "injusticias" de sexo, de las formas de inclusión y exclusión social que en los espacios urbanos encuentran el primer lugar de su definición material y simbólica.

${ }^{6}$ A escala mundial, la pobreza afecta de manera desproporcionada a las mujeres y las niñas: 330 millones de mujeres y niñas viven con menos de 1,90 dólares de los Estados Unidos al día, 4,4 millones más que en el caso de los hombres. Los datos, relativos a 89 países, muestran que hay 4,4 millones más de mujeres que viven en la extrema pobreza en comparación con los hombres. Gran parte de esta desigualdad se explica debido a la carga desproporcionada del trabajo doméstico no remunerado que enfrentan las mujeres, especialmente durante sus años reproductivos. "Las desigualdades en base al género aún existen en todos los países, en todos los grupos sociales y son relevantes en todas partes. Hemos hecho un análisis mirando a todos y cada uno de los Objetivos y en todos hemos encontrado que las mujeres están en peor lugar que los hombres", dice Sara Duarte Valero, experta en estadística de ONU-Mujeres que participó en la realización del informe ONU-Mujeres Informe: Hacer las promesas: La lgualdad de Género en la Agenda 2030 para el Desarrollo Sostenible, 2018.

${ }^{7} \mathrm{~A}$ nivel mundial, la tasa de actividad de las mujeres en el grupo de edad de máximo rendimiento (de 25 a 54 años) se sitúa en el $63 \%$, frente al $94 \%$ de sus homólogos de sexo masculino. La brecha salarial de género a nivel mundial es del 23\%. Cfr: op.cit ONU-Mujeres: Informe, 2018

${ }^{8}$ La Agenda 2030 como plan global para la erradicación de la pobreza, la lucha contra el cambio climático y la reducción de las desigualdades tiene un objetivo claro: lograr un mundo donde "nadie se quede atrás". En concreto significa
Repensar la ciudad como un lugar plural y disminuir la insostenibilidad del desarrollo, que contiene desigualdades e intimidaciones, solo es posible si no se elude la cuestión de la relación entre el hombre y la mujer, de esa primera forma de globalización que "de una manera simple y antigua" llamamos patriarcado, modelo que ha encontrado su expresión más moderna en el capitalismo y el liberalismo de la ciudad contemporánea.

Hace tiempo que, a los análisis tradicionales de las relaciones de clase y de los conflictos en el espacio urbano, se han agregado investigaciones sobre las injusticias de género que demuestran cómo el espacio no es neutral y requiere respuestas no neutrales, porque está habitado por personas de diferente género que tienen necesidades diferentes y juegan diferentes roles en la vida cotidiana, comenzando por la división sexual del trabajo.

Para muchas mujeres las ciudades son espacios, no solo de exclusión social y discriminación, sino tambien de explotación, abuso y violencia, con la negación total del derecho a la ciudad y al ejercicio concreto de los derechos humanos. ${ }^{9} \mathrm{Si}$ es cierto que no puede haber justicia social sin justicia espacial y de género, esto es más difícil en las ciudades modernas, resultado de una planificación urbana que ha favorecido la urbs en lugar de la civitas, con el principio del funcionamiento urbano basado en la monofuncionalidad: la subdivisión del territorio por zonas homogéneas, cada una destinada a una actividad y a una única dimensión de la vida. ${ }^{10}$

que ese objetivo concierne a todos los países y a todas las personas: nadie está excluido, ni debe dejarse atrás en el camino necesario para llevar al mundo a la sostenibilidad.

${ }^{9}$ Las cifras exactas de violaciones y agresiones sexuales son muy difíciles de constatar por el miedo frecuente que tienen las supervivientes a la hora de denunciar. Sin embargo, aproximadamente 15 millones de adolescentes (de edades entre 15 y 19 años) de todo el mundo han sufrido relaciones sexuales forzadas en algún momento de su vida. Es más, 3.000 millones de mujeres y niñas viven en países en los que la violación conyugal no está explícitamente penalizada. Una de cada cinco mujeres y niñas menores de 50 años denunció haber sufrido violencia física o sexual a manos de una pareja íntima en un período de 12 meses. Cfr ONU-Mujeres Informe, 2019

${ }^{10}$ Los congresos, la revistas, los manuales, entre los años veinte y treinta, se multiplicaron en todas partes sobre el tema de la zonificación como parte integral del debate planteado por el Movimiento Moderno. En el primer Congreso Internacional de Arquitectura Moderna (CIAM) en 1928, Le Corbusier insiste en la centralidad de una tríada de funciones, vivir, trabajar, recrearse, a las que deben responder la ciudad y la planificación urbana con sus medios, que serán codificados, en el Cuarto Congreso en 1933, con la llamada Carta de Atenas y la zonificación que se define como "esa operación realizada en el mapa de una ciudad para asignar a cada individuo el lugar que le corresponde". Se basa en la necesaria discriminación entre las diferentes actividades humanas que requieren su propio espacio particular. 
De esta forma, la ciudad funcionalista ha creado un orden urbano profundamente estructurado alrededor de la organización productiva y el hombre-trabajador, que reconoce solo el valor del tiempo que se puede monetizar y no el de otros sujetos, como las mujeres y su trabajo de reproducción y cuidado. Este orden ha determinado un uso privado del territorio en el que se niegan muchos derechos como a la movilidad: pocas líneas de transporte público, pocas oportunidades de movimiento para quienes no tienen vehículos privados, falta de reconocimiento de las necesidades de la movilidad de cuidado, que afectan principalmente a las mujeres.

Esta falta de atención a las personas, a su vida cotidiana, aumenta los espacios de segregación social de todas las diferencias de género, también de edad y de habilidades, y genera fragmentos de tejido urbano cuya recomposición unificada se vuelve más difícil para un desarrollo equilibrado, sostenible e integrado de la ciudad.

Las ciudades no son solo un conjunto de casas, son también un conjunto de relaciones, que van a dibujar un modelo social, dinámicas de convivencia y condiciones materiales que permiten implementar los planes de la vida y los sueños de todas y todos los que viven en ellas. Pero hay planes y sueños de personas, comenzando para las mujeres, que a nadie le importan.

Necesitamos nuevos paradigmas para la planificación urbana: una gramática que, desde la división sexual del trabajo y la microfísica de la vida cotidiana de las mujeres, estructure microarquitecturas de tiempos y espacios, medidas concretamente con el ritmo y los cuerpos diferentes de todas y de todos los que viven en la ciudad, para organizar espacios públicos seguros, viviendas, servicios adecuados, accesibilidad y

\footnotetext{
${ }^{11}$ Hábitat III es la Conferencia de las Naciones Unidas sobre la Vivienda y el Desarrollo Urbano Sostenible celebrada en Quito, Ecuador, del 17 al 20 de octubre de 2016. Fue la tercera de una serie de conferencias que las Naciones Unidas se comprometieron a convocar cada veinte años (1976, 1996 y 2016), con el objetivo de renovar el compromiso global con la urbanización sostenible de las ciudades y asentamientos humanos, tanto urbanos como rurales, a través de la construcción de una Agenda Urbana. El 20 de octubre de 2016 en Quito, durante la Conferencia, fue adoptada la Nueva Agenda Urbana que establece una estrategia global para el futuro de las ciudades para los próximos 20 años, después de la Agenda Urbana Hábitat II en Estambul en 1976

${ }^{12}$ El Objetivo 5: de la Agenda 2030: Lograr la igualdad entre los géneros y empoderar a todas las mujeres y las niñas es uno de los 17 Objetivos de Desarrollo Sostenible, que incluyen desde la eliminación de la pobreza hasta el combate al cambio climático, la educación, la igualdad de la mujer, la defensa del medio ambiente o el diseño de nuestras ciudades, de la
}

movilidad que garanticen efectivamente a todas las personas el derecho a vivir con dignidad y libertad en todos los lugares de nuestras ciudades, siempre, de día y de noche, con pleno equilibrio de todas las dimensiones de la vida.

Para este desafío necesitamos, básicamente, de un cambio estructural y de una nueva visión de las ciudades para el futuro, no solo como motor para el desarrollo económico y la prosperidad, sino tambien para la igualdad de las oportunidades, la inclusion social y la justicia de género.

\section{La Conferencia Habitat III y la Nueva Agenda Urbana}

¿Cómo pueden tomar forma estas nuevas visiones de ciudades?; ¿cómo las ciudades pueden convertirse en lugar y vehículo para el cambio?

Estas fueron las preguntas que estaban detrás de la gran movilización de las mujeres para la Conferencia de Habitat III ${ }^{11}$ durante el proceso de la Nueva Agenda Urbana y de la Agenda 2030 para el desarollo sostenible, que resultaron fundamentales para el reconocimiento de las cuestiones de género en varios párrafos, en particular, el 5 y el 13 de la NUA, en el objetivo 5 y transversalmente en todos los ODS de la Agenda 2030. ${ }^{12}$

La Nueva Agenda Urbana (NAU), aprobada durante la Conferencia Hábitat III ${ }^{13}$ parece ofrecer una oportunidad para abordar las desigualdades de género en las áreas urbanas, porque:

i. tiene como objetivo concretar los principios de las políticas, la planificación de espacios urbanos inclusivos, así como proporcionar la accesibilidad a los servicios básicos, mirando

Agenda 2030 sobre el Desarrollo Sostenible, que la ONU aprobó,en 2015,como una oportunidad para que los países y sus sociedades emprendan un nuevo camino con el que mejorar la vida de todos, sin dejar a nadie atrás.

${ }^{13}$ La Nueva Agenda Urbana es el nuevo programa para las ciudades de la ONU: "Declaración de Quito sobre ciudades sostenibles y asentamientos humanos para todos" que establece una estrategia global para el futuro de las ciudades para los próximos 20 años (2036). La NAU reafirma el compromiso mundial de promover el desarrollo urbano sostenible, que será un paso esencial para lograr un desarrollo sostenible integrado y coordinado a nivel mundial, regional, nacional, subnacional y local, con la participación de todos los interesados. La implementación de la Nueva Agenda para las Ciudades contribuye a la implementación y adaptación local e integrada de la Agenda 2030 para el Desarrollo Sostenible, incluido el Objetivo 11, que tiene como objetivo hacer que las ciudades y los asentamientos humanos sean inclusivos, seguros, resistentes y sostenibles. 
a las ciudades como una importante fuerza de desarrollo global, y planteándose el reto de cómo gestionar el proceso de urbanización para mejorar la vida de todos y todas;

ii. representa una guía para la urbanización sostenible para una amplia gama de actores -estados, ciudades y regiones, financiadores internacionales para el desarrollo, los programas de las Naciones Unidas, y la sociedad civil- para los próximos 20 años.

En la Nueva Agenda Urbana, los Estados Miembros afirman su compromiso con el principio de "ciudades para todas las personas", que promueve la inclusión y garantiza que:

"todos los habitantes, de las generaciones presentes y futuras, sin discriminación de ningún tipo, puedan habitar y producir ciudades, asentamientos humanos justos, seguros, saludables, accesibles, asequibles, resilientes y sostenibles, para fomentar la prosperidad y la calidad de vida para todas las personas".

La NAU es también un catalizador y acelerador de otras agendas internacionales de desarrollo, entre ellas: la Agenda 2030 para el Desarrollo Sostenible y sus Objetivos de Desarrollo Sostenible (ODS), el Acuerdo de París sobre Cambio Climático, el Marco de Sendai para la Reducción del Riesgo de Desastres, la Agenda de Acción de Addis Abeba sobre financiamiento para el desarrollo y la Cumbre Humanitaria Mundial.

${ }^{14}$ Desde mayo de 2015, se han obtenido grandes resultados durante el proceso de Hábitat III: las agencias de todas las Naciones Unidas y otros publicaron 22 "documentos temáticos", elementos clave de diversos sectores y áreas temáticas en las tendencias de urbanización de hoy. Desde agosto de 2015 hasta febrero de 2016, un grupo de 200 expertos, conocidos como "unidades de política", formularon recomendaciones importantes para la redacción e implementación de la Nueva Agenda Urbana.Una extensa serie de eventos oficiales y semioficiales, que incluyen reuniones regionales y temáticas, han producido documentos y declaraciones temáticas y de evaluación específicas.

En todo este proceso, expertos en género y mujeres líderes de base participaron activamente y proporcionaron una serie de declaraciones y recomendaciones para cada uno de estos documentos y para todas las declaraciones.

Las mujeres han desempeñado un papel activo, también, en la Campaña Urbana Mundial (WUC) y en la Asamblea de Socios de Género (GAP), dando aportes y recomendaciones sobre temas clave que se abordarán en la Nueva Agenda Urbana que se han lanzado colectivamente como LA CIUDAD QUE NECESITAMOS 2.0

${ }^{15}$ WPCG (Women's Partners Constituent Group) es el Grupo de Mujeres de los Socios Constituyentes, uno de los 18 grupos de socios constituyentes (PCG) de la Asamblea General de Socios (GAP) de ONU-Hábitat, que incorpora los principales grupos de agentes urbanos. Son Presidentas: Teresa BocCIA - AFEM (Association Femmes Europe Méridionale) y Magdalena GARCIA-HuAIROU Commission.

AGGI (Advisory Group on Gender Issues) es el Grupo Asesor
Las redes de mujeres han sido actores eficaces en la redacción de todas estas diferentes Agendas de desarrollo sostenible y la movilización de las mujeres ha acompañado, también, todo el largo y complejo camino de construcción de la Nueva Agenda Urbana, que es el resultado de un extenso proceso de consultas y participación de tres años ${ }^{14}$.

El trabajo conjunto de académicas y mujeres de base en diferentes organizaciones, principalmente del Grupo de las Mujeres de los Socios Constituyentes (WPCG), el Grupo de AGGI (Advisory Group on Gender Issues), el Centro de Género de UNI, la Comisión Huairou y ONU-Mujeres ${ }^{15}$, jugó un papel muy importante para introducir la óptica de género en la NAU.

Pero, ¿ dónde está el género en el texto definitivo de la Nueva Agenda Urbana?

La Nueva Agenda Urbana asume compromisos de género, garantizando la plena participación de mujeres y niñas y la igualdad de derechos en las ciudades. Reconoce la brecha entre la contribución de las mujeres a las ciudades y los beneficios que obtienen, en términos de representación en la gobernanza urbana, acceso a trabajo decente y a los servicios básicos, a la vivienda y a los espacios públicos, y subraya la importancia de abordar las desigualdades de género a lo largo del proceso de gestión y desarrollo urbano, en particular

de alto nivel sobre Asuntos de Género del Director de ONU Habitat que se formó en 2012, después del Foro Urbano Mundial 6 en Nápoles, para promover el empoderamiento de las mujeres y la igualdad de género en el desarrollo urbano sostenible. Los objetivos y función de AGGI son: la orientación y el asesoramiento estratégicos sobre políticas y programas de trabajo a nivel global, regional, nacional y local, las evaluaciones de género de las resoluciones en el contexto amplio de ONU-Habitat para un trabajo coherente sobre el empoderamiento de las mujeres y la igualdad de género. La Presidenta de AGGI es la profesora Ana Falù, de Argentina; las representantes europeas son la profesora Teresa Boccia de Italia y la profesora Inés Sánchez de Madariaga de España.

Gender Hub es el Núcleo de Género en UNI -Universidades Internacionales Articuladas-, de UN-Hábitat, que se constituye en 2013. Es coordinadora Ana Falú, directora del INVI$\mathrm{HAB}$ de Córdoba, Argentina, y la MGDH, en la Universidad Nacional de Córdoba, Argentina, y vice coordinadora Teresa Boccia, Profesora e Investigadora de urbanismo y género de LUPT, Universidad Federico II, Nápoles, Italia.

Huairou Commission es una organización que aglutina a una red de asociaciones de mujeres de todo el mundo. Fue creada durante la Conferencia Mundial de Mujeres de Beijing de 1995, de ahí su nombre tomado de la ciudad china en que las mujeres de base fueron confinadas. Tiene su sede en Nueva York y a través de los años ha movilizado a muchas mujeres de base de todo el mundo sobre cuestiones relacionadas con la vivienda y las zonas urbanas, en el contexto de conferencias y políticas de la ONU. 
en el párrafo cinco del Preámbulo y en el párrafo trece de "Nuestro ideal común". ${ }^{16}$

Las mujeres y el género son mencionados en el texto hasta treinta y siete veces. Este número de referencias claras en la Nueva Agenda Urbana, junto con los Objetivos de Desarrollo Sostenible, establece un marco nuevo y ambicioso para implementar políticas que aborden los temas de género en la planificación y sin duda se puede considerar un éxito. Sin embargo, una mirada más cercana a lo que implican invita a una evaluación diferente porque la mayoría de las referencias parecen ser formales, simples menciones a las mujeres o al género.

Más específicamente, se pueden identificar algunas áreas temáticas que requieren especial atención para lograr la igualdad de género y el empoderamiento de las mujeres y las niñas en el contexto del desarrollo urbano sostenible delineado en la NAU: la eliminación de la discriminación, de la violencia y de prácticas nocivas contra las mujeres y las niñas; el empoderamiento económico, el liderazgo y el acceso a la toma de decisiones de las mujeres; el acceso universal a los servicios de la salud, también sexual y reproductiva, adecuados; las infraestructuras físicas y sociales urbanas sensibles al género que tienen en cuenta la división sexual del trabajo; las políticas de vivienda con perspectiva de género; la seguridad de la tenencia de la tierra para las mujeres; las políticas de reducción del riesgo de desastres y de adaptación al cambio climático que responden a las instancias de género.

Las acciones enfocadas en estas áreas de todas las redes de mujeres, son necesarias para acelerar el progreso hacia una implementación sensible al género de la Nueva Agenda Urbana y para contribuir al progreso en todos los Objetivos de Desarrollo Sostenible de la Agenda 2030.

Para implementar acciones en estas áreas e incorporar efectivamente la perspectiva de género en la NUA, todas las partes interesadas deberían, sin embargo, dar prioridad a políticas que, teniendo en cuenta la interseccionalidad, promuevan acciones transformadoras para la igualdad de género con

\footnotetext{
${ }^{16}$ NAU: párrafo 5 del Preambulo:... la Nueva Agenda Urbana ayudará a poner fin a la pobreza y al hambre en todas sus formas.

NAU: párrafo 13 de "Nuestro común ideal": Imaginamos ciudades y asentamientos humanos que:

c) Logran la igualdad de género y empoderan a todas las mujeres y las niñas asegurando la participación plena y efectiva de las mujeres y la igualdad de derechos en todas las esferas y en los puestos de liderazgo en todos los niveles de adopción de decisiones, garantizando el acceso a un trabajo
}

financiación adecuada, estadísticas desagregadas por género, y, a nivel local, la participación activa de los múltiples agentes interesados, partiendo de las organizaciones de mujeres de base.

Una oportunidad importante para reflexionar sobre esto fue la Asamblea de Mujeres ${ }^{17}$, en la que participaron mil mujeres de más de 40 países, organizada en Quito, en el marco de la Conferencia Hábitat III, para formular recomendaciones para un desarrollo urbano sensible al género y para identificar las acciones mas incisivas dirigidas a alcanzar:

"ciudades donde podamos circular libremente, donde tengamos menos autos y mas servicios públicos, donde lo colectivo prime sobre lo individual. Donde tengamos tan buen transporte público que no necesitemos usar coches individuales y amenazar el medio ambiente con las emisiones de gases. En donde podamos circular en bicicleta tranquilas a cualquier hora, sin temer que nos vayan a violar, a acosar o a golpear" (Ana Falú, 2016).

La Asamblea de Mujeres se articuló en grupos de trabajo y estudió en profundidad algunas áreas temáticas fundamentales: garantizar el desarrollo urbano sensible al género; presentar una visión más amplia de la estrategia de implementación; identificar acciones para fortalecer las redes y las alianzas de mujeres; promover el liderazgo y una agenda de las mujeres a nivel nacional, que se pueda traducir en acciones concretas, con una perspectiva de género $y$, a nivel local, incluso en barrios marginales y asentamientos informales para identificar indicadores y mecanismos que permitan medir los objetivos logrados en una perspectiva de género.

El rico debate ha producido varias evaluaciones sobre el texto de la Nueva Agenda Urbana en aprobación de la Conferencia. Han sido evaluados como elementos positivos: la visión de la NAU que se alinea con el ODS 5 de la Agenda 2030, para impulsar ciudades y asentamientos humanos que promueven la igualdad de género y la emancipación de las mujeres y las niñas; la formulación de políticas sensibles al género en la planificación urbana y en el reconocimiento de los derechos de las mujeres y de las niñas a los servicios básicos,

decente y el principio de igual remuneración por igual trabajo, o trabajo de igual valor, para todas las mujeres y previniendo y eliminando todas las formas de discriminación, violencia y acoso contra las mujeres y las niñas en espacios públicos y privados:

f) Promueven la planificación basada en la edad y el género e inversiones para una movilidad urbana sostenible, segura y accesible para todos

17 L'Asamblea de las Mujeres fue organizada en colaboración con el Grupo de Mujeres de GAP de Habitat III ONU-Habitat. 
las infraestructuras, la seguridad y la seguridad alimentaria; el reconocimiento de que los espacios públicos y los medios de transporte deben ser seguros, mejorando la movilidad de las mujeres y su estatus social; el compromiso de apoyar el trabajo de las mujeres, incluso en la economía informal, y la necesidad de empoderar a las mujeres y las niñas en el mundo como líderes activas en las ciudades y comunidades.

Otros aspectos que también aparecen, aunque son más cuestionables son: la persistencia del concepto de fondo de las mujeres como una categoría entre los grupos vulnerables, lo que indica poca promoción de políticas de cambio estructural; las herramientas de implementación de la NAU que han sido consideradas muy genéricas, amplias y que no incluyen acciones incisivas para que las mujeres, en su diversidad, puedan ser socias y líderes en los temas del desarrollo urbano y del género.

\section{Después de la Conferencia Habitat III}

Desde la adopción de la Nueva Agenda Urbana, entre los agentes más comprometidos con la implementación de la NAU hay las redes de mujeres y sus organizaciones de base. Tanto las ONG como las expertas académicas han comenzado a experimentar nuevos caminos, produciendo nuevos conocimientos y nuevas visiones para su implementación, y promoviendo la adopción de presupuestos de género en todas las políticas urbanas nacionales y locales.

Para este propósito, se ha prestado mucha atención al Borrador del Marco de Acción para la Implementación de la Nueva Agenda Urbana (AFINUA $)^{18}$, preparado por ONU-Hábitat y adoptado en abril de 2017, que tiene el objetivo de establecer los ingredientes esenciales para la implementación de la NUA y que identifica como compromisos de transformación la inclusión social y la erradicación de la pobreza, la prosperidad y las oportunidades para todos, el desarrollo sostenible y resiliente, en cinco áreas sustantivas: políticas urbanas nacio-

${ }^{18}$ Los pilares de AFINUA son: Principios y Valores (PV): Urbanización y Desarrollo Sostenible (USD), Políticas urbanas nacionales (NUP), Reglas y Regulaciones (RR), Urbanismo y Diseño (UPD), Financiación de la urbanización (FI), Servicios Básicos Urbanos (UBS), Mejora de vivienda y barrios marginales (HSU), Investigación y desarrollo de capacidades (RCD), Derechos humanos (HR), Cambio Climático $(\mathrm{CC})$, Género (GE), Jóvenes $(\mathrm{Y})$, Implementación local (LI).

${ }^{19}$ El Foro Urbano Mundial (WUF) fue establecido en 2001 por las Naciones Unidas para abordar uno de los problemas nales (NUP), legislación urbana, normas y reglamentos, urbanismo y diseño, economía urbana y finanzas municipales.

Una implementación sensible al género de la Nueva Agenda Urbana debe traducirse, de hecho, en resultados prácticos para las mujeres transversalmente en todas las áreas y en todas las políticas: de la política urbana nacional a las politicas urbanas locales.

Para esto, en los últimos tres años desde la aprobación de la NUA, el compromiso de las redes de mujeres nunca se ha detenido en todos los eventos importantes que se han sucedido para su implementación.

\subsection{WUF $9 \mathrm{KL}$ : Noveno Foro Urbano Mundial de ONU-Habitat}

En Kuala Lumpur, Malasia, se celebró del 7 al 13 de febrero de 2018 el Noveno Foro Urbano Mundial "Ciudades 2030: Ciudades para todas las personas" 19 en el que se convocó, también, una Asamblea de Mujeres. Para prepararla se puso en marcha una plataforma en línea que facilitara mantener conversaciones productivas entre las mujeres y sus redes. La plataforma permitió el intercambio de recursos, de temas de importancia y de conocimiento antes de la Asamblea. También fue un mecanismo de seguimiento para continuar el trabajo, las discusiones y el intercambio de herramientas que se plantearon en el Foro Urbano Mundial.

En la Asamblea de Mujeres celebrada en Kuala Lumpur se discutieron los logros y los desafíos enfrentados desde la adopción de la Nueva Agenda Urbana y cómo los grupos de mujeres lideran los esfuerzos para una implementación sensible al género de la Nueva Agenda Urbana y de los Objetivos de Desarrollo Sostenible.

El grupo de mujeres compartió sus experiencias, perspectivas, herramientas y conocimientos con el objetivo de crear un mecanismo general para involucrar a las mujeres en la creación de ciudades que

que enfrenta el mundo hoy en día: la rápida urbanización y su impacto en las comunidades, ciudades, economías, cambio climático y políticas. Convocado por ONU-Hábitat, el Foro es una plataforma de alto nivel, abierta e inclusiva para abordar los desafíos de la urbanización sostenible. El Foro Urbano Mundial tiene entre sus objetivos mejorar el conocimiento colectivo sobre el desarrollo urbano sostenible a través del debate abierto e inclusivo, el intercambio de mejores prácticas y políticas, y el intercambio de lecciones aprendidas. En 2020 el WUF será en la ciudad de Abu Dhabi, Emiratos Arabes con el tema: "Cultura e innovación". 
sean sostenibles, resilientes, seguras e inclusivas para todas las personas. LaAsamblea se articuló en Grupos de trabajo de diez áreas temáticas clave ${ }^{20}$, que han desarrollado un paquete muy amplio y sustancial de recomendaciones específicas, entre las cuales se señala la necesidad de:

1. financiación pública para que las mujeres sean elegidas para los gobiernos locales y para apoyar las políticas y los servicios públicos para mujeres y niñas;

2. cuotas de género para promover la representación de las mujeres en los gobiernos locales;

3. visualización de la disparidad de género en las ciudades, incluyendo la edad y la interseccionalidad de las identidades;

4. incorporación del género en todas las políticas urbanas;

5. espacios y servicios con centro en la vida cotidiana para asumir la perspectiva de género, apoyo al empoderamiento de las mujeres y a la transformación de las normas sociales y de las estructuras de poder;

6. inversiones en infraestructuras adecuadas y sostenibles que faciliten el desarrollo y el enlace urbano- rural, sin dicotomía;

7. recursos financieros de los gobiernos locales y centrales para la regeneración urbana de los barrios marginales y de los suburbios;

8. seguridad en la tenencia de la tierra para las mujeres y reconocer el impacto de género en este problema;

9. cerrar la brecha entre las intenciones de las políticas y la práctica. Los gobiernos locales deben estar abiertos a un proceso que incluya monitoreo con perspectiva de género para rendir cuentas:

10. solucionar la presión comercial sobre la tierra para el desarrollo urbano que impacta y conduce al desalojo forzoso con una fuerte dimensión de género. Necesidad de soluciones más participativas para la planificación de asentamientos, compensación adecuada y restauración de medios de vida;

11. herramientas de documentación sobre los derechos a la tierra más participativas, a favor

\footnotetext{
20 1. Fortalecer el rol de las mujeres en los gobiernos locales: desafíos y oportunidades, 2. Espacios públicos seguros y accesibles para todos, incluida la movilidad de las mujeres y el transporte público, 3. Vínculos urbanos rurales y seguridad alimentaria, 4. Mejora de barrios marginales y provisión de servicios básicos sensibles al género, 5 . Tierra y propiedad, 6 . Incorporación de la perspectiva de
}

de los pobres, y asequibles, para mejorar la seguridad de la tenencia y los derechos de vivienda de las mujeres;

12. participacion de las mujeres en todos los niveles de toma de decisiones en la planificación, implementación de políticas y monitoreo, por ejemplo, en la planificación del uso de la tierra, la prevención y respuesta ante desastres y la adaptación y mitigación del cambio climático;

13. garantizar el género durante los desastres y en la evacuación, con la provisión de iluminación adecuada y características de seguridad en los centros de evacuación, teniendo en cuenta la privacidad de las familias para preservar la dignidad e involucrar las mujeres en el desarrollo del diseño y la planificación de planes de contingencia y espacios de evacuación;

14. alfabetización financiera para las mujeres y reconocimiento legal de su trabajo no remunerado;

15. voces en la gobernanza, participación y liderazgo de las mujeres también en los partidos políticos, en las asociaciones entre las comunidades y los gobiernos, pago por cuidado en el hogar;

16. nuevos términos para la "inclusión de mujeres con discapacidades", como "entorno inclusivo" porque no son las personas las que tienen discapacidad sino el entorno que no lo apoya;

17. construcción de compromiso / asociación con otros grupos como los grupos profesionales, grupos de base entre los cuales no hay cooperación, con el fin de obtener acceso a la información;

18. desarrollo de capacidades para las planificadoras urbanas, arquitectas y contratistas, integrando este tema en su educación, con cursos en las universidades u otras instituciones educativas:

19. producción y uso de datos desglosados por género, utilizando una lente interseccional, también sobre la migración para tener información cuantitativa y cualitativa;

20. liderazgo de la ayuda humanitaria a nivel loca que incluya a las organizaciónes de base;

21. involucración de los medios de comunicación en proyectos con mujeres refugiadas y migran-

género ante la emergencia / RRD / cambio climático, 7 . Inclusión económica de mujeres y niñas en las ciudades, 8. Inclusión de mujeres con discapacidad en un entorno urbano: educación / transporte salud /servicios económicos, 9. Crisis humanitarias y migración, 10. Incorporando el género en el Derecho a la Ciudad, lo que funciona, lo que aún debe hacerse. 
tes para cambiar los estereotipos sobre las migraciones;

22. participación activa, significativa e inclusiva de toda la diversidad de mujeres y niñas en el gobierno, la planificación y los servicios urbanos en todos los niveles;

23. producción de legislación continua (es decir, CEDAW) e implementación más sólida de la legislación y vías / acceso a la justicia para las mujeres.

Todas estas recomendaciones puntuales mostraron claramente que cada objetivo de desarrollo sostenible puede estar relacionado con la juventud y el género, que las ciudades son motores del crecimiento y que cada persona residente tiene los mismos derechos humanos.

Para incorporar de manera significativa el género como un tema transversal, la Asamblea de Mujeres en Kuala Lumpur ha producido también recomendaciones generales para una mayor efectividad del impacto de género en la estructura de ONU-Habitat, que se refieren a los siguientes aspectos:

i. fortalecimiento de la arquitectura y la capacidad en materia de género de ONU-Habitat para incorporar de manera significativa el género como un tema transversal en todo su trabajo operacional y normativo (desarrollo de capacidades de su propio personal, capacitación en programación sensible al género según diferentes áreas temáticas, particularmente en la Unidad de Género y en el Núcleo de Género de UNI);

ii. creación de una plataforma para diferentes socios, incluidas las agencias de la ONU que trabajan en temas de mujeres y ciudades para incorporar la perspectiva de género en la NAU;

iii. elaboración de presupuestos específicos para la incorporación de la perspectiva de género en todo el trabajo de ONU- Hábitat, incluidos los programas y proyectos que respalda (financiera y sustantivamente);

iv. institucionalización del apoyo en línea, la orientación, la creación de capacidades (conferencias y seminarios en línea, recopilación de herramientas, etc.) sobre la implementación de la NAU y los ODS relacionados con las instancias de género;

v. recolección, producción, análisis e información de datos desagregados por género regular-

${ }^{21} \mathrm{http}: / /$ www.urbanicemalaysia.com.my/kl-declaration/

22 La Reunión de Expertos para reflexionar sobre la propuesta de contenido del "Informe Cuatrienal 2018 " para la NUA de ONU Habitat se celebró en Granada, España, del 20 mente en el marco del seguimiento / monitoreo e implementación sensible a género de la NAU y los ODS relacionados;

vi. requerimiento de un informe de las ciudades que refleje las experiencias y los desafíos en la implementación de la NAU y los ODS sensibles al género como complemento a los informes oficiales (ver el informe paralelo de ONG CEDAW como un precedente).

vii. reforzamiento de los vínculos entre los diversos grupos de personas que trabajan para incorporar la perspectiva de género en la agenda de Hábitat (organizaciones de base, profesionales, académicos, agencias de la ONU, gobierno, etc.).

La novena sesión del Foro Urbano Mundial-WUF9 en Kuala Lumpur terminó con una "Declaración de Kuala Lumpur sobre Ciudades 2030" que reconoció varias tendencias y desafíos típicos de nuestro mundo cada vez más urbanizado ${ }^{21}$. El concepto de ciudad para todas las personas en la Declaración apela a la ciudad justa, segura, saludable, accesible, asequible, resiliente y sostenible en un entorno de prosperidad y calidad de vida. Apela a la ciudad que debería ser, a la ciudad a la que la comunidad internacional aspira.

El texto apuesta por el concepto de ciudades para todas las personas, muy en línea con la Agenda 2030 y su compromiso de no dejar nadie atrás. Un concepto que parece tener una comunicación eficaz pero que no tiene en concreto el desarrollo teórico, el anclaje social o el valor político del derecho a la ciudad. La Declaración, en esencia, no ha servido mucho para avanzar desde la adopción de la Nueva Agenda Urbana, no presta especial atención a la igualdad de género y al empoderamiento de las mujeres y las niñas en el contexto del desarrollo urbano sostenible, y no refleja el gran trabajo producido durante la Asamblea de las Mujeres.

\subsection{El Informe Cuatrienal \\ y el Foro Político de Alto Nivel sobre el Desarrollo Sostenible}

Unos meses despues el WUF 9 -Noveno Foro Urbano Mundial de ONU-Habitat- se celebró en Granada, España ${ }^{22}$, una Reunión de Expertos 
para reflexionar sobre la propuesta de contenido del Informe Cuatrienal 2018 y subsiguientes, para el seguimiento, revisión e implementación de la Nueva Agenda Urbana (NAU), incluidos los ODS urbanos. El objetivo de esta reunión fue recibir insumos y fortalecer alianzas entre socios para la implementación de la Nueva Agenda Urbana, desarrollar estrategias, una hoja de ruta y el enfoque para la preparación de los informes cuatrienales posteriores y para elaborar un borrador completo del primer Informe Cuatrienal, incluyendo los artículos de discusión de fondo, los puntos de debate y las recomendaciones.

El informe se basa en datos cualitativos y cuantitativos, recopilados en los últimos 2 años (20162018), y demuestra que las ciudades son cada vez más desiguales. Las desigualdades territoriales se están agravando, con una dramática concentración de desventajas en lugares y personas específicas. Las áreas urbanas aparecen cada vez más como epicentros de crisis, inseguridad y violencia, alimentando el desplazamiento y la migración forzada. Más de 1.600 millones de personas viven en viviendas inadecuadas, de los cuales mil millones viven en barrios marginales y asentamientos informales. Hasta 25 millones de refugiados y 40 millones de desplazados internos son a menudo integrados en áreas urbanas en condiciones difíciles. Lo dramático es que el informe destaca que todas estas formas de exclusión continúan afectando desproporcionadamente a las mujeres, los jóvenes, las personas mayores, los migrantes y otros grupos marginados. Este informe hace una serie de recomendaciones en materia de género entre las que cabe destacar la de elaborar evaluaciones de impacto de género de los planes y proyectos.

El Foro Político de Alto Nivel de la ONU sobre Desarrollo Sostenible (HLPF) celebrado en Nueva York en 2018, con el tema "la transformación hacia sociedades sostenibles y resilientes", centró la atención y el compromiso de muchas redes de mujeres. ${ }^{23}$ El HLPF, convocado bajo los auspicios del Consejo Económico y Social, es la principal plataforma de las Naciones Unidas para el desarrollo sostenible y tiene un papel central en el

\footnotetext{
${ }^{23}$ El sistema de seguimiento y revisión de los ODS se apoya en las Revisiones Nacionales Voluntarias (VNR,) por sus siglas en inglés) enviadas periódicamente por cada país al HLPF. El Foro adopta declaraciones políticas negociadas intergubernamentales.

${ }^{24}$ EI HLPF ha revisado el progreso en el 2018 en los siguientes objetivos: ODS 6. Garantizar la disponibilidad y la gestión sostenible del agua y el saneamiento para todos; ODS 7. Garantizar el acceso a energía asequible, confiable, sostenible y asentamientos humanos sean inclusivos, seguros, resilientes
}

seguimiento y la revisión de la Agenda 2030 para el Desarrollo Sostenible y sus 17 Objetivos de Desarrollo Sostenible (ODS) a nivel mundial. EI HLPF revisa el progreso hacia los ODS y en el año 2018 se centró en seis objetivos, entre ellos el undécimo ODS ${ }^{24}$ que está estrechamente vinculado a la Nueva Agenda Urbana: hacer que las ciudades y los asentamientos humanos sean inclusivos, seguros, resilientes y sostenibles.

Para apoyar una revisión en profundidad del progreso en el Objetivo 11, ONU-Habitat, junto con otras agencias y socios de las Naciones Unidas, ha producido un Informe de síntesis ODS 2018 sobre ciudades y comunidades sostenibles ${ }^{25}$ relacionado con otras agendas relacionadas, como la Nueva Agenda Urbana, el Acuerdo de París, el Marco Sendai, entre otros, que también fue una herramienta útil para la reflexión de las mujeres.

En el Foro Político de Alto Nivel, gracias, una vez más, a la movilización de las mujeres y de sus redes, ha sido confirmada la vinculación de los ODS con la Nueva Agenda Urbana, así como la necesidad de la incorporación de la perspectiva de género para apoyar los vínculos intrínsecos entre el desarrollo urbano sostenible y la igualdad de género que se confirma como un tema transversal.

El Foro aprobó, al final, una Declaración que reafirma el compromiso con los Objetivos de Desarrollo Sostenible, con 164 países a favor, ninguna abstención y dos en contra: Estados Unidos e Israel. En particular, reafirma que no hay paz sin desarrollo, ni desarrollo sin paz, que el desarrollo no solo es una herramienta de prevención de conflictos, sino que también fomenta condiciones para sociedades resilientes y un mundo pacífico, que el multilateralismo es la única forma de abordar los desafíos complejos, interconectados y de largo plazo que enfrentamos, y que los Pactos Mundiales para la Migración y sobre Refugiados son fundamentales para implementar la Agenda 2030.

El género en la Declaración del HLPF 2018 aparece específicamente en nueve de los treinta

y sostenibles; ODS 12. Garantizar patrones de consumo y producción sostenibles; ODS 15 . Proteger, restablecer y promover el uso sostenible de los ecosistemas terrestres, gestionar los bosques de manera sostenible, combatir la desertificación, detener e invertir la degradación de la tierra y detener la pérdida de la diversidad biológica; ODS 17. Fortalecer los medios de implementación y revitalizar la Alianza Global para el Desarrollo Sostenible, que será considerada cada año. ${ }^{25}$ https://www.onuhabitat.org.mx/index.php/foro-politico-dealto-nivel-ods-11 
y un párrafos ${ }^{26}$ donde se reafirma fuertemente, entre otras cosas, el compromiso de lograr la igualdad de género, el empoderamiento y la plena realización de los derechos humanos de todas las mujeres y niñas, de prevenir y responder a la violencia de género, la explotación y el abuso sexual, el acoso sexual y las prácticas dañinas, de producir, difundir, analizar y utilizar datos y estadísticas de calidad, desglosados por ingresos, sexo, edad, raza, etnia, estado migratorio, discapacidad, ubicación geográfica y otras características relevantes, de cerrar la brecha digital tanto entre países, como entre mujeres y hombres, y entre niñas y niños.

\section{4. ¿En qué estamos ahora? \\ 4.1. La reforma de ONU-Habitat}

Antes de pasar a hacer algunas consideraciones finales, es necesario decir algunas palabras previas sobre la reforma de ONU-Habitat, porque la Asamblea General de las Naciones Unidas decidió disolver la estructura de gobierno de ONU-Hábitat $^{27}$ para una nueva gobernanza del Programa de las Naciones Unidas para los Asentamientos
Humanos. ONU-Habitat, sin embargo, reafirma su función y sus conocimientos especializados dentro del sistema de las Naciones Unidas como centro de coordinación para la urbanización y los asentamientos humanos sostenibles, en particular en la aplicación, seguimiento y examen de la Nueva Agenda Urbana, en colaboración con otras entidades del sistema de las Naciones Unidas.

Antes de la reforma ONU-Hábitat fue estructurada en tres órganos principales:

- El Consejo de Gobierno (GC), cuya función fue establecer las principales direcciones estratégicas y políticas para ONU-Hábitat y aprobar sus programas y presupuesto. Fue compuesto por 58 estados miembros elegidos por el Consejo Económico y Social de la Asamblea General de las Naciones Unidas (ECOSOC).

- La Secretaría de ONU-Hábitat, cuya tarea fue garantizar la ejecución de las decisiones del Consejo de Gobierno y traducirlas en estrategias, programas e iniciativas específicas. La Secretaría fue el órgano ejecutivo de la organización. Con sede en Nairobi, Kenia, actúa como el punto focal para todos los asuntos de asentamientos urbanos y humanos dentro del sistema de las Naciones Unidas.
${ }^{26}$ Declaración del HLPF 2018, Parrafo 12. Debemos redoblar nuestros esfuerzos para resolver o prevenir conflictos y apoyar a los países que salen de un conflicto, incluso asegurando que las mujeres desempeñen un papel en la consolidación de la paz y la construcción del Estado... Parrafo 13... Imaginamos un mundo en el que todas las mujeres y niñas disfruten de la igualdad de género y se eliminen todas las barreras legales, sociales y económicas para su empoderamiento. Nos esforzaremos por un mundo donde las mujeres jóvenes y los hombres jóvenes sean agentes clave del cambio, apoyados por una cultura de innovación, sostenibilidad e inclusión...; Parrafo 16. Reafirmamos nuestro compromiso de lograr la igualdad de género, el empoderamiento de todas las mujeres y niñas y la plena realización de los derechos humanos de todas las mujeres y niñas. Para lograr sociedades inclusivas, sostenibles y resilientes, pedimos el liderazgo y la participación plena, efectiva e igualitaria de las mujeres en la toma de decisiones en el diseño, la elaboración de presupuestos, la implementación y el monitoreo de políticas y programas que afectan sus medios de vida, bienestar y resiliencia, y reconocemos que los roles genéricos desiguales, como se refleja en la proporción los roles genéricos desiguales, como se refleja en la proporción do y el trabajo doméstico, frenan a las mujeres en la economía y otras áreas. Reiteramos la urgencia de garantizar la igualdad de acceso y control de las mujeres a la tierra y los recursos naturales. Reafirmamos nuestro compromiso de prevenir y responder a la violencia de género, la explotación y el abuso sexual, el acoso sexual y las prácticas dañinas. Nuestros esfuerzos reforzarán los vínculos entre el Objetivo de Desarrollo Sostenible 5 y los otros Objetivos de Desarrollo Sostenible. La incorporación sistemática de una perspectiva de género en la implementación de la Agenda 2030 es crucial; Parrafo 18. Enfatice que los datos y estadísticas de alta calidad, accesibles, oportunos y confiables son fundamentales para la implementación de la Agenda 2030. Instamos a los países a fortalecer aún más la colaboración a nivel bilateral, regional y global para el desarrollo de capacidades y el intercambio de mejores prácticas para recopilar, producir, difundir, analizar y utilizar datos y estadísticas de calidad, desglosados por ingresos, sexo, edad, raza, etnia, estado migratorio, discapacidad, ubicación geográfica y otras características relevantes en el contexto nacional; Parrafo 21. Se comprometen a adoptar la diversidad en las ciudades y los asentamientos humanos, al fortalecimiento de la cohesión social, el diálogo intercultural y el entendimiento, la tolerancia, el respeto mutuo, la igualdad de género, la innovación; Parrafo 23... En particular, debemos prestar especial atención a garantizar el acceso a las instalaciones de saneamiento e higiene, teniendo en cuenta las necesidades específicas de las mujeres y las niñas, para la gestión de la higiene menstrual y para las personas con discapacidad, sin comprometer su seguridad y dignidad; Parrafo 25. Hacemos hincapié en la importancia de la planificación y el diseño urbano y territorial a largo plazo e integrado, destacando que las ciudades no deben desarrollarse de manera aislada de las áreas periurbanas y rurales circundantes y deben adoptar sistemas sostenibles, centrados en las personas, sensibles a la edad y al género. y enfoques integrados al desarrollo urbano y territorial; Parrafo 27 ...Incrementaremos los esfuerzos para facilitar la inversión en programas sensibles al género que aborden los problemas de deforestación, degradación de la tierra, desertificación, sequía, tormentas de arena y polvo, pérdida de biodiversidad y escasez de agua, incluso mediante la implementación del Plan Estratégico para los Bosques de las Naciones Unidas, el Bosque de las Naciones Unidas. Parrafo 29... Persiste una brecha digital sustancial, tanto entre países como dentro de ellos y entre mujeres y hombres, y entre niñas y niños. Hacemos hincapié en la necesidad de actuar de manera proactiva para evitar exacerbar las desigualdades entre los países y dentro de ellos en los próximos años, y que la introducción de nuevas tecnologías nunca debe impedirnos el compromiso de no dejar a nadie atrás.

${ }^{27}$ Resolución A / RES / 73/239 aprobada por la Asamblea General el 20 de diciembre de 2018. 


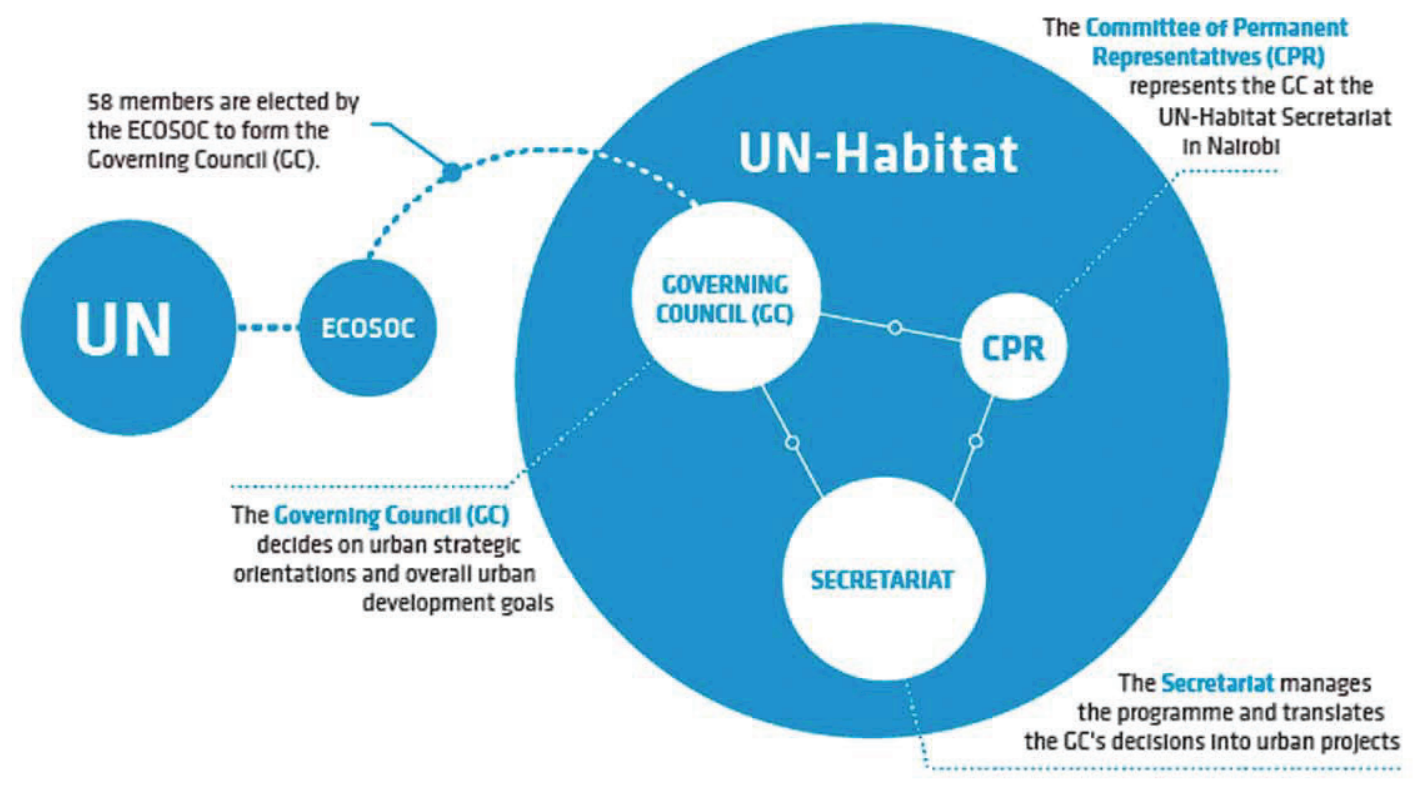

Fig. 1/ Estructura de ONU-Hábitat antes de la Reforma.

Fuente: https://oldweb.unhabitat.org/structure-overview/

- El Comité de Representantes Permanentes (CPR), que aseguró que las decisiones del Consejo de Gobierno sean promulgadas por la Secretaría dentro del marco establecido. Tiene una función de supervisión y representa al Consejo de Administración en la Secretaría para abordar los problemas que surgen entre las reuniones bienales del Consejo de Administración. EI CPR fue compuesto por embajadores o enviados extranjeros de los estados miembros acreditados ante ONU-Hábitat.

La nueva estructura está formada por tres niveles:

- Asamblea de ONU-Hábitat: un organismo universal compuesto por los 193 estados miembros de las Naciones Unidas y que se reúne

${ }^{28}$ Miembros del Comité Ejecutivo: A. África (10 representantes): Camerún, República Democrática del Congo, Nigeria, Senegal Egipto, Marruecos, Etiopia, Kenia, Angola, Malawi; B. Asia-Pacífico (8 representantes): Sri Lanka, Republica de Corea, China, Japón, India, Irán, Indonesia, Paquistan; C. Europa del Este cada cuatro años en la sede de ONU-Hábitat en Nairobi;

- Junta Ejecutiva: un organismo compuesto de treinta y seis estados miembros ${ }^{28}$, elegido para la Asamblea de ONU-Hábitat, que se reúne tres veces al año para aumentar la supervisión de los Estados miembros de las operaciones de ONU-Hábitat. Los países actualmente elegidos para Europa occidental y otros estados son: Canadá, Francia, Suecia, Turquía, Estados Unidos, Alemania, España, Portugal;

- Comité de Representantes Permanentes de ONU-Hábitat (CPR por sus siglas en inglés) que se reúne dos veces cada cuatro años de manera abierta.
(4 representantes) Polonia, Federación Rusa, Serbia, Rumanía D. América Latina y el Caribe (6 representantes):Argentina, Brasil, Chile, Costa Rica, México, Uruguay; E. Europa Occidental y otros (8 representantes): Canadá, Francia, Suecia, Turquía, Estados Unidos de América, Alemania, España, Portugal. 
CyTET LII (203) 2020

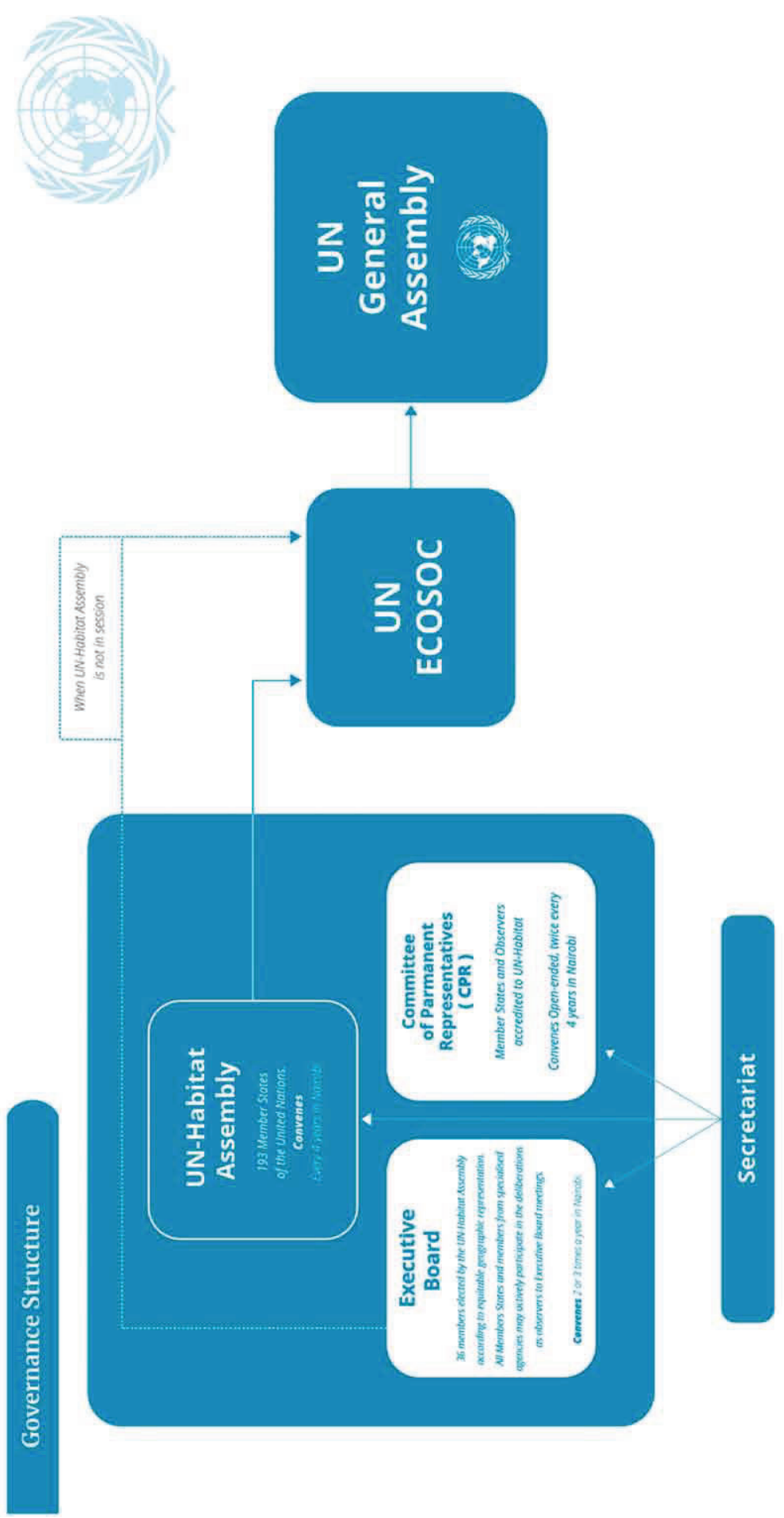




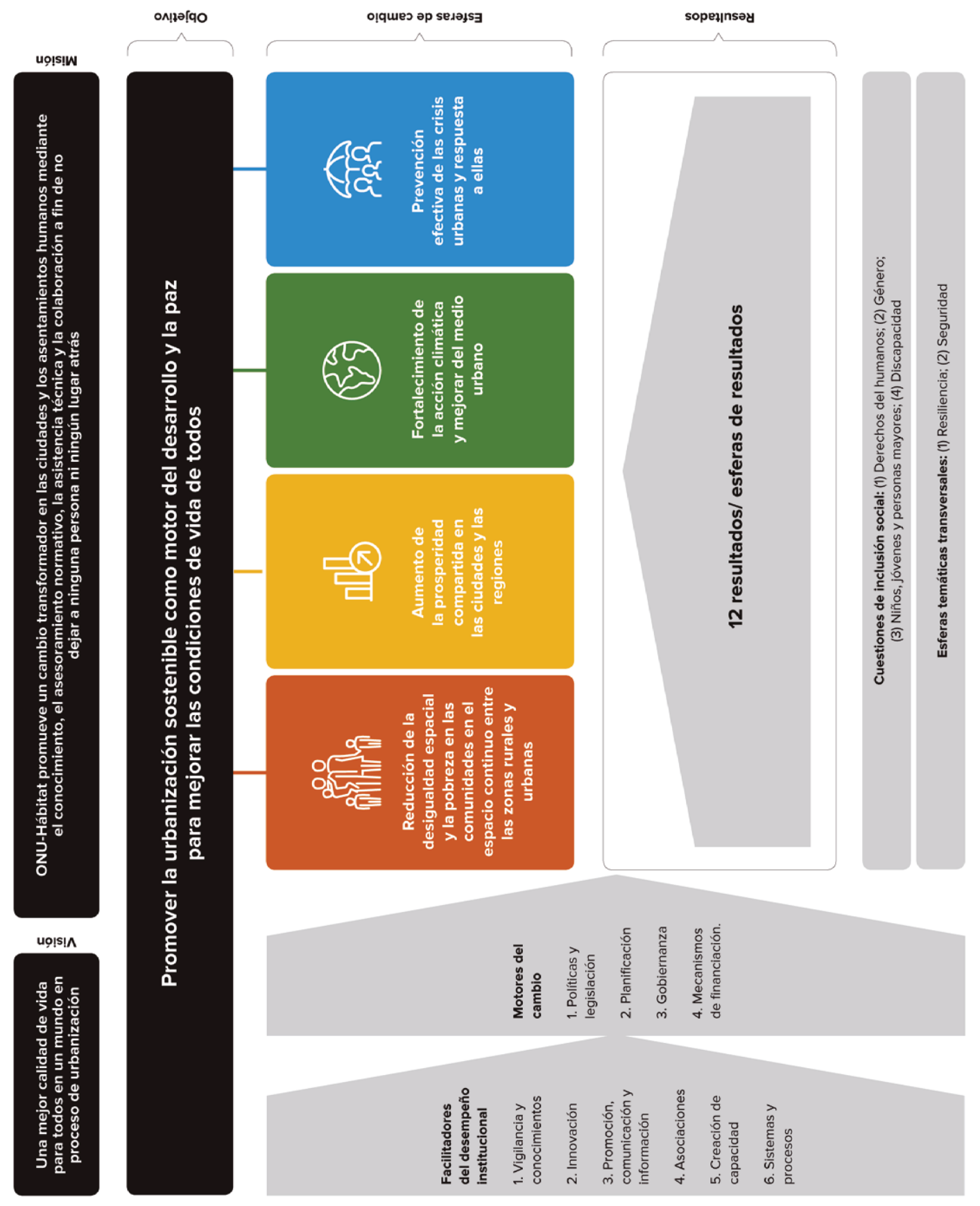

FIG. 3/ Teoría del cambio de ONU-Hábitat para el plan estratégico para el período 2020-2023.

Fuente: ONU-Hábitat: El plan estratégico 2020-2023 
La primera Asamblea General de la nueva gobernaza de ONU-Hábitat se convocó en Nairobi (Kenya), del 27 al 31 de mayo de 2019, con el tema central:

"La innovación para mejorar la calidad de vida en ciudades y comunidades: aplicación acelerada de la Nueva Agenda Urbana para avanzar hacia el logro de los Objetivos de Desarrollo Sostenible".

Durante los cinco días de sesiones de trabajo y actividades paralelas, con la participación de 127 países, han sido elaboradas cuatro Resoluciones sobre el desarrollo de capacidades para la implementación de la Nueva Agenda Urbana y una Resolución de Género y el Plan Estratégico 2020-2025 de ONU-Habitat en favor de ciudades resilientes y sostenibles.

En particular, el Plan Estratégico 2020-2025 es de extraordinaria importancia porque delinea el marco de las políticas de ONU-Hábitat para los próximos años. En su proceso de elaboración estuvo guiado por una teoría del cambio y posiciona a ONU-Hábitat como un centro de excelencia e innovación para promover la urbanización sostenible y como motor del desarrollo y la paz, en consonancia con el principio de los ODS de "no dejar a nadie atrás", y del ODS 11 de lograr que las ciudades y los asentamientos humanos sean inclusivos, seguros, resilientes y sostenibles, así como con todos los principios y compromisos de la Nueva Agenda Urbana.

Las "esferas de cambio" identificadas son: reducción de la desigualdad espacial y la pobreza en las comunidades y en el espacio continuo entre las zonas rurales y urbanas; aumento de la prosperidad compartida en las ciudades y las regiones; fortalecimiento de la acción climática y mejora del medio urbano; prevención efectiva de las crisis urbanas y respuesta a ellas. Estas esferas se sustentan en las dimensiones de inclusión social: los derechos humanos, el género, los niños, los jóvenes, las personas mayores, la discapacidad y en las temáticas trasversales: la resiliencia y la seguridad.

En el proceso de preparación de la Primera Asamblea de ONU-Hábitat se convocó en Nairobi, dos días antes, el Primer Foro Mundial de las Partes Interesadas con el objetivo de promover una estrategia de colaboración de las partes interesadas

${ }^{29}$ En la Declaración del Primer Foro Mundial de las Partes Interesadas de ONU-Habitat se llama a:...erradicar todas las formas de desigualdad y barreras a la gobernanza equitativa y al desarrollo en los asentamientos humanos, tal como se practica especialmente contra las mujeres, los hogares encabezados por mujeres, los jóvenes, los niños y otros"....."Nos comprometemos con los gobiernos nacionales, subnacionales y locales, las agencias de la ONU, la sociedad civil, el sector privado y otras partes interesadas que trabajan juntas en todos los niveles y son cruciales para el logro de los ODS y de la Nueva Agenda Urbana en las ciudades y las comunidades.

EI Primero Foro Mundial de las Partes Interesadas ha terminado con una Declaración, elaborada por un Grupo Consultivo de expertos de alto nivel de dieciséis miembros que asumió el cargo durante el Foro, si bien no ha prestado especial atención a la igualdad de género y el empoderamiento de las mujeres y las niñas en el contexto del desarrollo urbano sostenible. De nuevo, gracias a todos los esfuerzos de las redes de mujeres presentes, se ha mejorado la primera formulación con dos párrafos añadidos y, por lo menos, las mujeres ya no aparecen entre los gupos vulnerables. ${ }^{29}$

\subsection{La contribución de la red de mujeres en la Primera Asamblea \\ de la nueva gobernanza de ONU-Hábitat}

En Nairobi ha habido, una vez más, un gran activismo y un trabajo extraordinario de las redes de mujeres en muchos eventos para reiterar la necesidad de acciones concretas para la igualdad de género y el empoderamiento de las mujeres en el desafío para el desarrollo urbano sostenible. Cabe destacar en particular los siguientes:

En primer lugar, el Panel "Igualdad de Género y Mujeres"30, organizado durante el Primer Foro Mundial de las Partes Interesadas, en el que fueron reconocidos como elementos críticos: el enfoque del Plan Estratégico 2020-2025, que tiende a considerar de nuevo a las mujeres como parte de los grupos vulnerables y receptoras de políticas para la inclusión social, y la tendencia a orientar las políticas de las mujeres más sobre la no discriminación y la inclusión que sobre el empoderamiento. La discusión del Panel terminó con varias recomendaciones que han solicitado:

1. financiación dedicada a programas para mujeres: es un elemento básico para apoyar la igualdad entre mujeres y hombres a través el empoderamiento, la reducción de las si-

a trabajar con organizaciones de mujeres y de mujeres de base como agentes estratégicos y socios en estos esfuerzos."

${ }^{30}$ Las oradoras en el Panel representando a los grupos de Mujeres fueron Teresa Boccia (Presidenta Honoraria de la Asociación de Mujeres de la Europa Meridional, AFEM) e Inés Sánchez de Madariaga (Vicepresidenta AFEM). 
tuaciones existentes de discriminación y desigualdad, y para abordar específica y directamente las situaciones, acumuladas también históricamente, de vulnerabilidad o desventaja de las mujeres.

2. Apoyo a organizaciones de mujeres de base y asociaciones de mujeres: las organizaciones de base representan la voz de las mujeres más desfavorecidas en todo el mundo, cuya voz no se escucharía si no se contempla la financiación para su participación en el proceso de políticas. Por tanto, el apoyo también debería incluir la orientación a los gobiernos sobre el apoyo a las asociaciones y a las organizaciones de mujeres de base.

Desde este Panel se produjeron también recomendaciones para el Plan Estratégico 2020-2025 de ONU-Habitat y para la Resolución de Género. Más específicamente se recomendó lo siguiente:

1. una evaluación obligatoria de impacto de género, ex-ante y ex-post de todos los programas, planes y proyectos del Plan Estratégico 2020-2025. Esta evaluación debe ser obligatoria para tener algún efecto. La legislación debe describir su contenido mínimo. Se trata de identificar los impactos esperados antes de que se establezca la política, lo que permite su mejora desde el principio y, después, a fin de monitorear y evaluar los impactos reales en mujeres y hombres. Las evaluaciones de impacto de género se deben incluir como una herramienta para promover la igualdad de género según se adoptó en el Informe Cuatrienal que establece los criterios para la evaluación y el monitoreo de la implementación de la Nueva Agenda Urbana.

2. La implementacion de procesos de responsabilidad social participativa con una perspectiva de género. Tales procesos garantizarán la responsabilidad social de las políticas, programas, planes y proyectos y la inclusión de las voces de diferentes grupos dentro del proceso de responsabilidad.

3. La activación de sistemas para incentivar acciones de igualdad de género y apoyo a las mujeres en el sector privado: La acción dentro del sector público y los gobiernos no es suficiente para promover la igualdad de género y los derechos de las mujeres en la ciudad. El sector privado también debe contribuir a este proceso. Se pueden diseñar diferentes tipos de sistemas de incentivos para este objetivo, que incluyen, entre otros, los sistemas de reconocimiento y concesión de premios, tales como los que otorgan sellos de calidad y otros; disposiciones dentro de los procedimientos de contratación pública que dan algunos puntos adicionales a las empresas que integran algunos tipos de políticas de igualdad de género en su plan de negocios y gestión de recursos humanos, etc.

4. El fortalecimiento de la estructura administrativa a cargo del género en ONU-Habitat: estas estructuras deben ser creadas con suficiente personal y recursos económicos. También es importante garantizar que el personal tenga experiencia en cuestiones de género.

En segundo lugar, otro foro importante celebrado durante la Asamblea General de ONU-Habitat fue el "Foro de Género sobre las Mujeres y la Nueva Agenda Urbana: lograr la igualdad de género y el empoderamiento de las mujeres en las ciudades a través de enfoques innovadores" que ha sido convocado con el fin de:

1. explorar enfoques innovadores para mejorar la movilidad de las mujeres, el acceso al espacio público y la mejora de los vínculos urbano-rurales,

2. enfatizar el poder del análisis de género usando datos verificables para explorar cómo pueden ayudar a identificar las brechas y las intervenciones necesarias para el desarrollo,

3. hacer hincapié en la necesidad de políticas y programas sensibles al género en el desarrollo urbano sostenible.

La discusión en el Foro ha sido articulada en grupos sobre cuatro temas: invertir en la igualdad de género, igualdad de género para todas, mujeres en el liderazgo y seguridad para las mujeres en las ciudades.

Un tercer ámbito de discusión importante ha sido el Caucus de Mujeres ${ }^{31}$ : cada mañana, una gran coalición de grupos del movimiento de mujeres que incluía a la Comisión de Huairou, mujeres profesionales, mujeres de base, mujeres en el mundo académico y de la sociedad civil, se han reunido para revisar el Plan estrategico 20202025 en detalle y para compartir evaluaciones, problemas críticos, y pioridades.

${ }^{31}$ El Caucus de Mujeres fue un espacio gestionado por la

y organizaciones que compartiron nuevos enfoques, eventos clave y oportunidades de participación. 
Resultado final de todas estas múltiples actividades y Foros de debate e intercambio ha sido la conclusión de que el Plan Estratégico es neutral en cuanto al género y no apoya suficientemente el empoderamiento y la igualdad de las mujeres. Este Plan se refiere en la mayoría de los casos a las mujeres como un grupo de inclusión social, mientras que sería necesaria su participación activa como agentes y no como víctimas o receptoras, algo fundamental para la realización de los OSD. De hecho, el empoderamiento económico de las mujeres aumenta la productividad, aumenta la diversificación económica y es un motor documentado de mejoras económicas para todos.

Han sido identificadas, también, como prioridades de género las siguientes: la aceleración del progreso hacia la igualdad de género; la identificación de las mujeres y su experiencia en sus comunidades como innovadoras, líderes de opinión y agentes de cambio y no solo como receptoras de protección y servicios; la promoción de políticas para que las mujeres estén presentes en paridad en los espacios de toma de decisiones, la implementación de indicadores de género como guía para diseñar programas y determinar inversiones; la garantía de uso de datos desagregados de género y de su producción sistemática a través de la normativa.

En el marco para la implementación, han sido identificadas como acciones importantes, un programa para que las mujeres compartan las mejores prácticas en la implementación de los OSD y de la Nueva Agenda Urbana y proyectos de formación para acelerar la igualdad y para que las mujeres puedan participar más plenamente en los procesos de desarrollo sostenible y de gobierno.

La contribución de las mujeres a la primera Asamblea de la nueva gobernanza de ONU-Hábitat se enriqueció, tambien, de acciones y actividades del Grupo Asesor sobre Asuntos de Género (AGGI por sus siglas en inglés) ${ }^{32}$, que fueron muy intensas ya en los meses anteriores de la primera Asamblea de ONU-Habitat convocada en Nairobi. En particular para:

1. IPlan Estratégico de ONU-Hábitat 2020-2025 para el que han sido producidos comenta-

\footnotetext{
${ }^{32}$ AGGI (Advisory Group on Gender Issues): Grupo Asesor de alto nivel sobre Asuntos de Género de ONU-Habitat.

${ }^{33}$ Resolución 24 / XX del 2013: Igualdad de género y empoderamiento de las mujeres para contribuir al desarrollo urbano sostenible.

${ }^{34}$ La embajadora de Costa Rica en Nairobi es Marta E. Juárez.

${ }^{35}$ Resolución 1/1: Plan estratégico del Programa de las $\mathrm{Na}$ ciones Unidas para los Asentamientos Humanos para el período 2020-2023.

Resolución 1/2: Directrices para todo el sistema de las Naciones
}

rios y aportes al borrador cero, ya desde noviembre 2018, para garantizar que tenga en cuenta las cuestiones de género. Se han producido observaciones generales, articuladas en treinta y seis puntos para enfatizar que el género no es solo uno de los temas de inclusión social, sino que la realización de la igualdad de género y el empoderamiento de las mujeres es un requisito estratégico para la misión y la visión de la Agencia, contribuyendo así al logro de los Objetivos de Desarrollo Sostenible (ODS) y de la Nueva Agenda Urbana. Se destacó, tambien, que los temas referidos a mujeres y al género en este Plan Estratégico están en veintiséis de los doscientos siete párrafos.

2. La preparación del borrador de una Resolución de Género que AGGI consideró, en previsión de la primera Asamblea de Hábitat de las Naciones Unidas, muy importante para que la nueva gobernanza empezara su nuevo camino de trabajo con un compromiso sobre cuestiones de género. Por esta tazón AGGI comenzó a trabajar en un borrador de una Resolución de género que actualizara la Resolución de género anterior ${ }^{33}$ y volviera a confirmar el compromiso para lograr la igualdad entre los géneros. El factor decisivo para dicha Resolución, que solo puede ser presentada por un país miembro, fue la presencia en AGGI de un estado miembro, designado por el CPR, la embajadora de Costa Rica en Kenia ${ }^{34}$.

De hecho, entre las cinco Resoluciones aprobadas durante la Primera Asamblea de ONU-Habitat, ${ }^{35}$ se ha producido una Resolución de Género ${ }^{36}$ patrocinada por Costa Rica y presentada por Costa Rica, Colombia, Noruega, Chile, Uruguay y la Unión Europea. Indudablemente su aprobación ha sido el resultado de una gran alianza y de un gran trabajo entre representantes de los gobiernos, miembros de AGGI, asociaciones y organizaciones de mujeres de base, porque su camino no fue fácil, a partir de las deliberaciones del Comité de Redacción para la Resolución.

Unidas sobre ciudades y asentamientos humanos más seguros. Resolución 1/3: Perfeccionamiento de la creación de capacidad para la aplicación de la Nueva Agenda Urbana y la dimensión urbana de la Agenda 2030 para el Desarrollo Sostenible. Resolución: Mejora de los vínculos urbano-rurales para la urbanización sostenible y los asentamientos humanos.

${ }^{36}$ Proyecto de Resolución sobre la integración de la igualdad de género para apoyar ciudades inclusivas, seguras, resilientes y sostenibles, y ciudades asentamientos

https://papersmart.unon.org/sites/default/files/Spanish 7.pdf 
Se comenzó con un cambio de título para indicar que la igualdad de género es el objetivo y el mainstreaming una herramienta para lograrlo y, en este sentido, el título fue enmendado así:

"Lograr la igualdad de género a través del trabajo de ONU-Hábitat para apoyar el desarrollo inclusivo, seguro, resiliente de ciudades sostenibles y asentamientos humanos",

Sin embargo, el debate más intenso fue sobre la terminología: algunos delegados solicitaron reemplazar las referencias a "género" por "hombres y mujeres" y también debatieron la referencia a los "servicios de salud sexual y reproductiva". Sobre el tema de la necesidad de recursos humanos y financieros adecuados, algunas delegaciones solicitaron que se haga hincapié en el carácter voluntario de las posibles contribuciones.

Ciertamente entre los puntos de acuerdo de los delegados fueron la marginación y la discriminación sistemática de las mujeres que "obstaculiza el pleno disfrute de los derechos humanos y es un impedimento para el logro de los ODS de la Agenda 2030 y de la Nueva Agenda Urbana, en referencia a la necesidad, además, de abordar las posibles implicaciones presupuestarias de las actividades incluidas en el proyecto de Resolución.

Pero, ¿cuál es el contenido principal de la Resolución de género aprobada? ${ }^{37}$ Se trata de varias solicitudes dirigidas a la Directora Ejecutiva de ONU-Hábitat:

1. que, con el apoyo de los Estados miembros, refuerce y preste su apoyo en la ejecución de una estrategia de género que incorpora la igualdad de género y el empoderamiento de la mujer en la normativa y los programas operacionales de ONU-Hábitat en todas las esferas de interés clave;

2. que instaure políticas y programas para apoyar los esfuerzos encaminados a lograr la igualdad entre los géneros y el empoderamiento de la mujer dentro de los límites de los recursos existentes;

3. que utilice los recursos disponibles para incorporar la perspectiva de género en los programas y las actividades de ONU-Hábitat, como se refleja en su plan estratégico para el período 2020-2023;

4. que asigne recursos suficientes para la elaboración y aplicación de una versión actualizada para el período 2020-2025 del plan de acción sobre la igualdad de género y el em-

\footnotetext{
${ }^{37}$ Resolución 1/4: Lograr la igualdad entre los géneros mediante la labor del programa de las Naciones Unidas para los asentamientos humanos en apoyo de ciudades y asentamientos
}

poderamiento de las mujeres en el desarrollo urbano y los asentamientos humanos, como complemento del plan estratégico para el mismo período, en el marco de los recursos existentes, y que, en la medida de lo posible, recabe recursos adicionales voluntarios;

5. que dialogue y coopere con las organizaciones de la sociedad civil, las mujeres dirigentes de autoridades locales, el sector privado, los medios de comunicación y las organizaciones femeninas y comunitarias de base, las organizaciones no gubernamentales, así como con los expertos, aprovechando sus conocimientos y liderazgo en el desarrollo sostenible, el tiempo que respeta la igualdad entre los géneros y tiene en cuenta las necesidades diferenciadas, principalmente de las mujeres y las niñas, a fin de mejorar la eficiencia y el impacto de los programas y las actividades;

6. que haga el mejor uso posible de su Grupo Asesor sobre Cuestiones de Género (AGGI), así como de otras redes pertinentes, para facilitar la incorporación de una perspectiva de género en ONU-Hábitat y la integración efectiva de la perspectiva de igualdad entre los géneros en sus políticas y programas dirigidos a aplicar su plan estratégico y programa de trabajo, a la hora de abordar una mejor paridad entre los géneros en la Organización;

7. que, a través de la Junta Directiva, presente un informe a la Asamblea de ONU-Hábitat en su segundo período de sesiones sobre la aplicación de la resolución.

La primeraAsamblea de ONU-Habitat estuvo marcada, también, por la aprobación de la Resolución 1/2: Directrices para todo el sistema de las Naciones Unidas sobre ciudades y asentamientos humanos más seguros, que también ha sido objeto de gran atención de las redes de mujeres para la importancia del tema de la seguritad en los espacios públicos urbanos sin violencia, como emergencia en el mundo por la falta del pleno ejercicio de los derechos humanos para las mujeres.

De hecho, entre los principios básicos de la Resolución se reconoce la inclusión, el género, la edad y la identidad cultural y en el apartado sobre la organización, método y enfoque:

"la necesidad de centrar la atención en la experiencia y la participación de la mujer, desde el diseño hasta la aplicación de las estrategias de prevención de la delincuencia y seguridad urbana, en el entendimiento de que una ciudad más segura

humanos inclusivos, seguros, resilientes y sostenibles, https://unhabitat.org/sites/default/files/documents/2019-07/ hsp ha.1 res.4 spanish.pdf 
para las mujeres es una ciudad más segura para todos. La participación de la mujer y la consideración de sus necesidades deberían estar integradas y consagradas en todas las iniciativas de prevención de la delincuencia y seguridad urbana".

\section{Conclusiones}

La Nueva Agenda Urbana delinea una visión que identifica en las ciudades el motor del desarrollo económico sostenible, la prosperidad, la inclusión y la justicia social, con la convicción que si las ciudades son los lugares donde surgen los problemas, también son aquellos donde las soluciones se pueden encontrar más fácilmente.

Pero todavía para muchas personas esto sigue siendo muy difícil. Ciertamente lo es para las instancias de género. La prosperidad en las ciudades no va de la mano con la igualdad de oportunidades para la mayoría de las mujeres y niñas que, en todo el mundo, continúan enfrentándose con la pobreza las discriminaciónes múltiples y la violencia.

Son muchas las acciones nacionales y locales que deben ser implemendadas con urgencia para romper barreras y desigualdades, agravadas para la crisis económica, la emergencia climática y la proliferación de conflictos, tal como las redes de mujeres repitieron tenazmente en los muchos documentos que produjeron y siguieron produciendo en las diversas reuniones de seguimiento desde la adopcion de la Nueva Agenda Urbana.

Necesitamos más esfuerzos para cambiar de rumbo las tendencias que no corresponden a los desafíos previstos. La fuerza de las mujeres y de su trabajo en redes ha dado lugar a muchas nuevas palabras para la igualdad de género en la Nueva Agenda urbana, pero no es suficiente. Muchas parecen dictadas más desde la lógica del "politically correct" o de la retórica que desde la convicción que las mujeres son un recurso estratégico para la innovación y el cambio hacia la sostenibilidad del desarrollo y la paz.

Las ciudades necesitan la acción de las mujeres. Sólo una sólida colaboración con ellas, sus organizaciones y sus movimientos, que conocen desde el terreno en la vida cotidiana las necesidades de las personas más invisibles, incluso en las nuevas formas de urbanización en que viven mujeres migrantes y refugiadas, puede ser una garantía para cumplir los objetivos de la Nueva Agenda Urbana, del derecho a la ciudad para todas y todos, el respeto de la dignidad humana y la democracia urbana.

Si avanzamos sin apoyar la participación de las mujeres y de sus movimientos, el éxito de la implementación de los ODS y de la NAU no será sus- tancial y no cambiará el paradigma en el futuro de las ciudades.

La agenda de las mujeres en el centro de las políticas urbanas nacionales no es sólo un imperativo moral, sino también una elección de realpolitik inteligente. La agenda de las mujeres es necesaria para mejorar el medio ambiente, abordar la resiliencia, recuperar la autosuficiencia alimentaria, promover la salud, y reducir la mortalidad materna e infantil. Es la política más segura para mejorar la nutrición, prevenir conflictos y lograr la reconciliación postconflicto. No existe una estrategia de desarrollo efectiva en la que las mujeres no desempeñen un papel central.

Hay muchas acciones, promovidas por la cultura y la acción de las mujeres, para introducir un enfoque dual y la incorporación de la perspectiva de género en los procesos de planificación de las ciudades, pero el proceso por el cual se convierten en políticas estructurales es muy lento y no hay más tiempo.

Poner en el centro de las transformaciones urbanas la complejidad de la vida cotidiana de las mujeres y de todas las personas que reclaman el derecho al bienestar, la equidad, la dignidad y la libertad en las ciudades es realmente una práctica posible o ¿sigue siendo una utopía feminista?

\section{Bibliografía}

Acierno,A. (2016): Reading the New Urban Agenda in a gender perspective International Journal of Urban Planning, special issue: towards Habitat III a gender perspective, Volumen. n. ${ }^{\circ}$ 16: pp.5-10

ARENDT, H, (1950): Quaderno I, 4, julio 1950.

Bauman, Zygmunt (2000): Liquid Modernity, Cambridge: Polity Press.

BocciA, T. (2003): El tiempo y el espacio de las ciudades: la experiencia italiana, Segundo Seminario Internacional Sobre Género y Urbanismo. Infraestructuras para la Vida Cotidiana ETSAM, UPM. 27 y 28 de mayo de 2002, ETSAM. Universidad Politécnica de Madrid.

- (2013): L'empowerment economico delle donne nella città, TRIA, Territorio della Ricerca su Insediamenti e Ambiente Volumen 10: pp. 23-34.

- (2016): Habitat III: theories and practices of the women facing the global challenges in cities. TRIA, International Journal of Urban Planning, special issue: towards Habitat III a gender perspective, Volumen 16: pp 17-20

Damyanovic, D. \& Reinwald, F. \& Weikmann A. (2013): Handbuch Gender Mainstreaming in der Stadtplanung, Vienna: Werkstattbericht.

FALÚ, A. (2011): "Restricciones ciudadanas: las violencias de género en el espacio público". En LARGARDE, M. \& VALCÁRCEL, A. (coord.): Feminismo, género e igualdad. Ed. Pensamiento Iberoamericano.

- (2016): Contribuciones de Género para la Implementación de la Agenda Urbana Habitat III, TRIA International Journal of Urban Planning, special issue: towards 
Habitat III a gender perspective, Volumen. $n^{\circ} 16$ : pp.11-16

FARÉ, I. (2013): Sapere femminile e cura della città, TRIA, Territorio della Ricerca su Insediamenti e Ambiente Volumen 10: pp. 85-92.

Moser, C. (2016): Gender transformation in a new global urban agenda: challenges for Habitat III and beyond, IIED, https://doi.org/10.1177/0956247816662573

- (2016): "Can the New Urban Agenda fundamentally transform gender relations?", Citiscope, 18 April, http://citiscope.org/habitatll//commentary/2016/04/ can-new-urban-agenda-fundamentally-transformgender-relations

Muxi MARTíneZ, Z. \& al. (2011): “¿Qué aporta la perspectiva de género al urbanismo?" FEMINISMOS, Instituto Universitario de Estudios de Género de la Universidad de Alicante, Volumen 17: pp 105-129.

NACIONES UNIDAS (2013): Resolución 24 / XX: Igualdad de género y empoderamiento de las mujeres para contribuir al desarrollo urbano sostenible.

- (2015): Transforming our world: the 2030 Agenda for Sustainable Development, Nairobi.

- (2015): Transforming Our World. The 2030 Agenda for Sustainable Development, New York: UN General Assembly.

https://sustainabledevelopment.un.org/content/ documents/21252030\%20Agenda $\% 20$ for $\% 20$ Sustainable\%20Development\%20web.pdf

[Accessed 10 June 2019].

- (2016): Report of the high-level political forum on sustainable development convened under the auspices of the Economic and Social Council at its 2016 session.

- (2016): Habitat III Revised Zero Draft of the New Urban Agenda, Nairobi.

- (2016): Nueva Agenda Urbana. Declaración de Quito, New York: UN General Assembly, 2016. https://www2.habitat3.org/file/537306/view/591158 [Accessed 10 June 2019].

- (2018): Progress on the implementation of the New Urban Agenda Report of the Secretary-General, New York: General Assembly.
- (2018): World Population Prospects 2019, Hihlights.

- (2019): Resolución 1/4: Lograr la igualdad entre los géneros mediante la labor del programa de las Naciones Unidas para los asentamientos humanos en apoyo de ciudades y asentamientos humanos inclusivos, seguros, resilientes y sostenibles.

Novella AbRIL, I. (2017): Recognition in architecture and urban planning. Reshaping the profession for the New Urban Agenda. TRIA, International Journal of Urban Planning, special issue: Engendering Habitat III: Facing the Global Challenges in Cities, Volumen. $n .{ }^{\circ}$ 17: pp 39-56

Onu MuJeres (2018): Informe: Hacer las promesas: La Igualdad de Género en la Agenda 2030 para el Desarrollo Sostenible.

Ortiz Escalante, S. (2016): Where is women's right to the night in the New Urban Agenda? The need to include an intersectional gender perspective in planning the night, International Journal of Urban Planning, special issue: towards Habitat III a gender perspective, Volumen. n. ${ }^{\circ}$ 16: pp:165-180

SÁnchez de Madariaga I. (2004): Urbanismo con perspectiva de género. Instituto Andaluz de la Mujer, Sevilla

- (2013): "Mobility of Care: Introducing New Concepts in Urban Transport". En: SÁnchez de MAdariaga, I. \& Roberts, M. (ed): Fair Shared Cities, Ashgate Publishing Limited.

- (2017): Implementing the New Urban Agenda: Research and Gender, TRIA, International Journal of Urban Planning, special issue: Engendering Habitat III: Facing the Global Challenges in Cities, Volumen. n. ${ }^{\circ}$ 17: pp 27-38

— \& BoccIA, T. (2017): Engendering Habitat III: Facing the Global Challenges in Cities, TRIA, International Journal of Urban Planning, special issue: special issue: Engendering Habitat III: Facing the Global Challenges in Cities, Volumen. $n .^{\circ} 17$ : pp 13-20

- \& Roberts, M, (2013): "The Impact of Gender Planning in Europe". En: Sánchez de Madariaga, I. \& Roberts, M. (ed): Fair Shared Cities, Ashgate Publishing Limited. 